\title{
Lumbar Puncture Findings in İnfants under 12 Months of Age with Simple Febrile Seizure
}

\author{
Mustafa Ciftci ${ }^{1}$, Firat Erdogan², Cagatay Nuhoglu³, Omer Ceran² \\ ${ }^{1}$ Pediatrics Department, Istanbul Medipol Hospital, İstanbul, Turkey \\ ${ }^{2}$ Pediatrics Department, Istanbul Medipol University, Istanbul, Turkey \\ ${ }^{3}$ Pediatrics Department, Haydarpaşa Numune Education and Research Hospital, Istanbul, Turkey
}

\begin{abstract}
:
Aim: The aim of the study was to asses the necessity of lumbar puncture in infants under 12 months of age with simple febrile seizure.

Material and Methods: The study group covered 33 infants less 12 months of age and diagnosed as simple febrile seizure. Lumbar puncture was performed for all the patients. The age, vaccination status, physical examination, laboratory results of patients are evaluated.
\end{abstract}

Results: White blood cell count, polymorphonuclear cell percentage or C-reactive protein levels are higher than normal in 12 patients but those are not statistically significant. in between the patients with meningitis and the others.

Conclusions: In conclusion, performing lumbar puncture routinely in infants with simple febrile seizure is not beneficial. Lumbar puncture should be done if signs of meningitis are present or in order to determine the origin of infection.

Keywords: Lumbar puncture, simple febrile seizure.

\section{INTRODUCTION}

Febrile seizures (FS) are the most common neurological problem in childhood. According to various studies the incidence of FS is $2 \%$ to $5 \%$. FS are classified as simple and complex. ${ }^{1-5}$ Most of the infections in FS are respiratory tract infections and the causative agents are the viruses generally. ${ }^{5,6}$

The American Academy of Pediatrics (AAP) at 1996 recommended strongly to perform lumbar puncture (LP) in infants with FS younger than 12 months of age and in children received prior antibiotic treatment or having meningeal irritation sign. Also LP should be considered for patients between 12 and 18 months of age since the clinical signs of meningitis may be subtle. ${ }^{1,7}$ However in the recent guideline of the AAP at 2011 LP is recommended in the presence of clinical signs of meningitis, for children 6 to 12 months of age whose immunization status for Haemophilus influenzae type $\mathrm{b}$ and Streptococcus pneumoniae is incomplete and also for children who had prior antibiotic treatment. ${ }^{8}$

In both guidelines the AAP did not recommend further evaluations in simple FS like electroencephalography (EEG), blood studies, or neuroimaging. Laboratory studies and neuroimaging should better be used in identifying the cause of fever or in differential diagnosis of simple FS. ${ }^{1,7-11}$

In this study our aim is to evaluate the lumbar puncture findings in infants under 12 months of age with simple febrile seizure in order to find out its necessity.

\section{Materíal AND Method}

In this retrospective research, the files of the patients that were diagnosed as febrile convulsion during the period between 01.01.2005 and 31.12.2006 in the Clinic of Pediatrics in Haydarpaşa Numune Education and Research Hospital were studied. Patients with complex FS, electrolyte or metabolic imbalance, nonfebrile convulsions and neurologic disorders were excluded. In order to determine the 
origin of fever, physical examinations of patients were made carefully. Also for his purpose laboratory tests like urine analysis, urine culture, blood culture and imaging modalities like chest roentgenogram were used.

The age, vaccination status, physical examination, laboratory findings of patients were evaluated. At that time LP was performed for all the patients younger than 12 months of age with FS according to the previous guideline of AAP. ${ }^{1,7}$ Before performing LP, necessity, procedure, risks and complications of LP were explaned to the parents and their permissions were taken. The lumbar punctures were performed by experienced staff according to general rules of the procedure. ${ }^{12,13}$

The cerebrospinal fluid (CSF) samples were analysed at the laboratories of biochemistry and microbiology in our hospital. The cell count of CSF was done under 40 times magnification with light microscope. Protein, glucose and chloride levels of CSF were analysed in Dade Behring 2 device in the laboratory of biochemistry. The CSF samples were cultured in aerobic, anaerobic and LöwensteinJensen medias and cultured bacterias were stained with Frotty, Giemsa and Gram stains. The complete blood count was analysed in the Coulter device, $\mathrm{C}$ reactive protein (CRP) levels were analysed in nephilometric way.

The parameters of the patients like age, sex, physical examination findings, presence of signs of meningitis and laboratory findings are analysed with the statistical analysis program, Graphpad İnstat 3.05. Rational comparison of values is analysed with Fisher's exact test, and measurable values are analysed with Mann Whitney U test. $p<0.05$ was considered significant.

\section{Results}

Thirty three patients were included in this study. All of them had simple FS and were younger than 12 months of age. According to AAP recommendations lumbar puncture were performed for all of them. ${ }^{1,7}$ Mean age is $7,30 \pm 3,74$ months and male female ratio is $1,35 / 1$, (Table 1 )

Table 1. Demographic features of the patients

\begin{tabular}{|l|l|}
\hline \multicolumn{1}{|c|}{ Number of cases } & \multicolumn{1}{|c|}{$\mathbf{3 3}$} \\
\hline Mean age (months) & $7,30 \pm 3,74$ \\
\hline Male/Female ratio & $19 / 14(1,35 / 1)$ \\
\hline
\end{tabular}

Etiological causes of fever in the study are upper respiratory tract infections $(\% 36,4, n=12)$, lower respiratory tract infections $(\% 18,2, \mathrm{n}=6)$, acute gastroenteritis $(\% 15,1, \mathrm{n}=5)$, urinary tract infections $(\% 6,1, \mathrm{n}=2)$, acute otitis media $(\% 6,1, \mathrm{n}=2)$, sepsis $(\% 6,1, \mathrm{n}=2)$, viral menengitis $(\% 9,0, \mathrm{n}=3)$ and bacterial menengitis $(\% 3,0, \mathrm{n}=1)$. ( Table 2$)$

Table2. Types of infections causing fever

\begin{tabular}{|l|l|l|}
\hline & \multicolumn{1}{|c|}{ Number of cases } & \multicolumn{1}{c|}{ \% of cases } \\
\hline Upper Respiratory Tract Infections & 12 & 36,4 \\
\hline Lower Respiratory Tract Infections & 6 & 18,2 \\
\hline Gastroenteritis & 5 & 15,1 \\
\hline Viral menengitis & 3 & 9,0 \\
\hline Urinary Tract Infections & 2 & 6,1 \\
\hline Acute Otitis Media & 2 & 6,1 \\
\hline Septisemia & 2 & 6,1 \\
\hline Bacterial meningitis & 1 & 3,0 \\
\hline Total & 33 & 100 \\
\hline
\end{tabular}

White blood cell counts (WBC) are higher than normal ranges in 9 patients and also polymorphonuclear (PNL) cell prodominance is seeen in these patients $(27,3 \%)$. CRP levels are higher than normal in 12 patients $(36,4 \%)$. Neither WBC count nor CRP values are statistically significant in between the patients with meningitis and the others. ( Table 3)

Table 3. Comparison of the laboratory findings of the patients with meningitis and the others

\begin{tabular}{|l|l|l|l|}
\hline & Meningitis (+) & Meningitis (-) & p value \\
\hline Mean WBC count \pm SD (standard deviation) & $15414 \pm 7308$ & $13025 \pm 6051$ & 0,5440 \\
\hline Mean CRP value (mg/dl) \pm SD & $7,42 \pm 12,20$ & $2,73 \pm 3,87$ & 0,4733 \\
\hline Mean PNL predominance & $50 \%$ & $24 \%$ & 0,2952 \\
\hline
\end{tabular}


In the study, four patients are diagnosed as meningitis. Three of them are viral origin and one of them is bacterial origin. Laboratory findings of the patient who has bacterial menengitis (Case-1) are 20900 white blood cell $/ \mathrm{mm} 3,77 \%$ of polymorphonüclear cell (PNL) in leucocyte count, $25,7 \mathrm{mg} / \mathrm{dL}$ value of CRP, $20 \mathrm{mg} / \mathrm{dL}$ CSF glucose level, $111 \mathrm{mEq} / \mathrm{L}$ CSF cloride level and 0,14 CSF/Blood glucose ratio. In physical examination of the Case-1 patient nuchal rigidity was observed as a sign of meningitis, but neither Kernig nor Brudzinski signs were observed. Also in CSF sample of the Case-1 patient 1000 cells were counted and Streptococcus Pneumonia was cultured. Laboratory findings of the patients with viral meningitis (Cases-2,3,4) are listed in Table 4.

Table4. Laboratory findings of the patients that were diagnosed as meningitis

\begin{tabular}{|l|l|l|l|l|}
\hline \multicolumn{1}{|c|}{ Cases } & \multicolumn{1}{c|}{2} & \multicolumn{1}{c|}{3} & \multicolumn{1}{c|}{4} \\
\hline Age (months) & 8 & 10 & 12 & 3 \\
\hline Cell count (CSF) & 1000 & 46 & 150 & 60 \\
\hline White blood cell count /mm3 & 20900 & 13100 & 6200 & 11900 \\
\hline PNL percentage & 77 & 56 & 60 & 68 \\
\hline CRP mg/dL & 25,7 & 2,1 & 1,0 & 0,89 \\
\hline CSF glucose mg/dL & 20 & 18 & 81 & 20 \\
\hline CSF cloride mEq/L & 111 & 121 & 114 & 122 \\
\hline CSF/Blood glucose & 0,14 & 0,56 & 0,71 & 0,22 \\
\hline Signs of meningitis & $(+)$ & $(-)$ & $(-)$ & $(-)$ \\
\hline CSF culture & $\begin{array}{l}\text { Streptococcus } \\
\text { Pneumonia }\end{array}$ & - & - & - \\
\hline
\end{tabular}

\section{Discussion}

Majority of FS are simple in nature. Simple FS has to be lasting less than 15 minutes, one convulsion within 24 hours and generalized type. Also meningitis, metabolic disorders and neurological abnormalities have to be absent in simple FS cases. ${ }^{1-5}$ Inspite of frightening cilinical aspect, prognosis of simple FS is excellent. ${ }^{7,14}$ Complications of FS are status epilepticus, recurrence of FS and epilepsy. Simple FS slightly increase the risk for epilepsy than normal population. ${ }^{7,14}$ The risk increases up to $2,4 \%$ if the first seizure occured in infants less than 12 months of age and if the patients had recurrent FS or positive family history for epilepsy. Studies has shown neither cognitive nor behavioral disturbance related to simple FS. ${ }^{15-17}$

After admission to hospital, airway, breathing and circulation status of patients $A B C$ of the emergency room, have to be supported firstly. Than if convulsion continues anticonvulsant therapy should be considered to cease the seizure. ${ }^{14,18}$ After that, clinicians should evaluate patients to find out the infection causing fever. Bacterial meningitis is the most serious infection in children. Analysing CSF sample is golden standart to diagnose meningitis. The procedure to take CSF sample is lumbar puncture that is a invasive complicated procedure and needs experienced staff, advanced laboratory facilities, has complications like bleeding, infection and even tonsillary herniation and cardiopulmoner arrest. It also causes a huge stress on parents of the patient. ${ }^{12,13,19-21}$

In our study, among 33 cases, only one patient is diagnosed as a bacterial meningitis. The patient was 8 months of age, not pretreated with any antibiotics. In physical examination nuchal rigidity was found. Laboratory findings of the patient that are high leukocyte count, PNL predominance and high CRP value, suggest a bacterial infection but those are not statistically significant. As a result, it is concleded that laboratory findings can not be used to evaluate the risk of meningitis in patients with FS like similar conclusions in literature. ${ }^{22,23}$

In developed countries, meningitis is a rare disease and its incidence is $0,23 \%$ in patients with FS . Whereas in developing countries due to low sociocultural level it increases to $0,4-1,2 \%$. The incidence rises up to $4,2 \%$ in underdeveloped contries. ${ }^{24-26}$ In our study the ratio of bacterial meningitis is $3 \%$ close to developing-underdeveloped countries.

FS could be the first and only symptom of meningitis in $24 \%$ of cases. ${ }^{27,28}$ Especially in infants younger than 12 months of age, meningeal irritation signs could be absent in $30-35 \%$ of cases. ${ }^{29,30}$ For that reason the AAP strongly advice to perform LP in previous guideline. ${ }^{1,7}$ However, due to the risks and complications LP as an invasive procedure is recommended only when it is necessary in many studies. ${ }^{32-34}$ In our study meningeal irritation signs were absent in viral meningitis cases whereas 
nuchal rigidity was observed in the bacterial meningitis case. According to our results, since antibiotics are not used in the treatment of viral meningitis, performing LP is worthless in the absence of meningitis sign. The lumbar puncture was already indicated in the bacterial meningitis case because of the presence of nuchal rigidity. Besides the AAP recomended that LP should be performed if there are clinical signs of meningitis in the recent guide at $2011 .^{8}$

Another reason to perform LP is the absence of the origin of fever. A clinician must take LP in consideration if the origin of fever cannot be found in a febrile patient. ${ }^{29,31,33}$ It is another indication for performing LP for the bacterial meningitis case in our study to find out the origin of fever.

In our study respiratory system infections are most common infections casusing fever and percentages of the other infections are similar to many studies. ${ }^{6,35}$ In addition, even an infection site is detected as an origin of fever like otitis media the patient may have meningitis too at the same time. ${ }^{29,36}$ No overlaping infections were detected in our study.

The AAP guideline at 2011, LP is adviced for children 6 to 12 months of age whose immunization status for Haemophilus influenzae type b and Streptococcus pneumoniae is incomplete or absent. ${ }^{8}$ In our study the bacterial meningitis patient was vaccinated for Haemophilus Influenzae type B, not for Streptococcus Pneumoniae according to routine vaccination scedule of Ministry of Health. The LP should be considered in this case according to AAP due to incomplete immunization status for $\mathrm{S}$ pneumoniae. As expected S. Pneumoniae was cultured in CSF sample.

In conclusion, our study reveals perfoming lumbar puncture and analysing the CSF sample routinely are not helpful in evatuation and treatment of the patients with simple febrile seizures. LP should be done if signs of meningitis are present.

\section{REFERENCES}

[1] American Academy of Pediatrics, Provisional Committee on Quality Improvement and Subcommittee on Febrile Seizures. Practice parameter: the neurodiagnostic evaluation of a child with a first simple febrile seizure. Pediatrics. 1996;97(5): $769-775$

[2] Joint Working Group of the Research Unit of the Royal College of Physicians and the British Paediatric Association. Guidelines for the management of convulsions with fever. BMJ 1991 Sep 14;303(6803):634-6.

[3] Freeman JM, Vinig EP. Decision making and the child with febrile seizures. Pediatrics in Review 1992 Aug;13(8):298-304.

[4] Hirtz DG, Nelson KB. Febrile seizures. In: Child and Adolescent Neurology, R.B. David (ed), Neurology Psychiatry Access Series, Mosby Year Book Inc. 1998; 551-561.

[5] Hirtz D. Febrile seizures. Pediatrics in Review 1997; 18:5-9.

[6] McIntyre PB, Gray SV, Vance JC. Unsuspected bacterial infections in febrile convulsions. Med Jour of Aust. 1990 Feb 19;152(4):183-6.

[7] Duffner PK, Baumann RJ. A synopsis of the American Academy of Pediatrics' practice parameters on the evaluation and treatment of children with febrile seizures. Pediatrics in Review 1999 Aug;20(8):285-7.

[8] Subcommittee on Febrile Seizures; American Academy of Pediatrics. Neurodiagnostic evaluation of the child with a simple febrile seizure. Pediatrics. 2011;127(2):389-394.

[9] Yang PJ, Berger PE, Cohen ME, Duffner PK. Computed tomography and childhood seizure disorders. Neurology. 1979;29(8): $1084-1088$

[10] Kuturec M, Emoto SE, Sofijanov N, et al. Febrile seizures: is the EEG a useful predictor of recurrences? Clin Pediatr (Phila). 1997; 36(1):31-36

[11] Jaffe M, Bar-Joseph G, Tirosh E. Fever and convulsions: indications for laboratory investigations. Pediatrics. 1981;67(5): $729-731$

[12] Shaked O, Peña BM, Linares MY, Baker RL. Simple febrile seizures: are the AAP guidelines regarding lumbar puncture being followed? Pediatr Emerg Care. 2009;25(1): 8 -11

[13] Kimia AA, Capraro AJ, Hummel D, Johnston P, Harper MB. Utility of lumbar puncture for first simple febrile seizure among children 6 to 18 months of age. Pediatrics. 2009; 123(1):6 -12

[14] Committee on Quality Improvement, Subcommittee on Febrile Seizures. The long-term treatment of the child with simple febrile seizures. Pediatrics. 1999;103:1307-1309 
[15] Ellenberg JH, Nelson KB. Febrile seizures and later intellectual performance. Arch Neurol. 1978;35(1):17-21

[16] Nelson KB, Ellenberg JH. Predictors of epilepsy in children who have experienced febrile seizures. N Engl J Med. 1976;295(19): 1029-1033

[17] Berg AT, Shinnar S, Darefsky AS, et al. Predictors of recurrent febrile seizures: a prospective cohort study. Arch Pediatr Adolesc Med. 1997;151(4):371-378

[18] American Academy of Pediatrics Steering Committee on Quality Improvement and Management, Subcommittee on Febrile Seizures. Febrile seizures: clinical practice guideline for the long-term management of the child with simple febrile seizures. Pediatrics. 2008;121(6):1281-1286.

[19] Carroll W and Brookfield D. Lumbar puncture following febrile convulsion. Arch. Dis. Child. 2002;87;238-240.

[20] American Academy of Pediatrics, Steering Committee on Quality Improvement and Management. Classifying recommendations for clinical practice guidelines. Pediatrics. 2004;114(3):874-877

[21] Graves RC, Oehler K, Tingle LE. Febrile seizures: risks, evaluation, and prognosis. Am Fam Physician. 2012 Jan 15;85(2):149-53. Review

[22] Yield of lumbar puncture among children who present with their first complex febrile seizure. Kimia A, Ben-Joseph EP, Rudloe T, Capraro A, Sarco D, Hummel D, Johnston P, Harper MB. Pediatrics. 2010 Jul;126(1):62-9.

[23] Sadleir LG, Scheffer IE. Febrile seizures. BMJ 2007 Feb 10;334(7588):307-11.

[24] Offringa M, Moyer VA. Evidence based paediatrics: evidence based management of seizures associated with fever. BMJ 2001;323:1111-4.

[25] Akpede GO, Sykes RM, Abiodun PO. Indications for lumbar puncture in children presenting with convulsions and fever of acute onset: experience in the Children's Emergency Room of the University of Benin Teaching Hospital, Nigeria. Ann Trop Paediatr 1992;12(4):385-9.

[26] Frequency of Meningitis in Children Presenting with Febrile Seizures at Ali-Asghar Children's Hospital. Tavasoli A, Afsharkhas L, Edraki A. Iran J Child Neurol. 2014 Fall;8(4):51-6.

[27] Green SM, Rothrock SG, Clem KJ, Zurcher RF, Mellick L. Can seizures be the sole manifestation of meningitis in febrile children? Pediatrics. 1993;92(4):527-534

[28] Chang YC, Guo NW, Wang ST, Huang CC, Tsai JJ. Working memory of school-aged children with a history of febrile convulsions: a population study. Neurology 2001;57:37-42.

[29] Rutten N, Smales OR. Role of routine investigations in children presenting with their first febrile convulsion. Arch Dis Child. 1977; 52:188-191.

[30] Ratcliffe JC, Wolf SM. Febrile convulsions caused by menengitis in young children. Ann Neurol 1977; 1: 285-286.

[31] Karatoprak N, Aladağ N, Yavrucu S, Özgüner A. Menenjitli olgularda konvülsiyonun değerlendirilmesi. Hipokrat dergisi 2002; 6 (11):112-114.

[32] Simple febrile seizures: are the AAP guidelines regarding lumbar puncture being followed? Shaked O, Peña BM, Linares MY, Baker RL. Pediatr Emerg Care. 2009 Jan;25(1):8-11.

[33] An assessment of the necessity of lumbar puncture in children with seizure and fever. Ghotbi F, Shiva F. J Pak Med Assoc. 2009 May;59(5):292-5

[34] Predicting factors and prevalence of meningitis in patients with first seizure and fever aged 6 to 18 months. Heydarian F1, Ashrafzadeh F, Rostazadeh A. Neurosciences (Riyadh). 2014 Oct;19(4):297-300.

[35] Trainor JL, Hampers LC, Krug SE, Listernick R. Children with first-time simple febrile seizures are at low risk of serious bacterial illness. Acad Emerg Med. 2001;8(8):781-787.

[36] Gerber MA, Berliner BC, The child with a simple febrile seizure: appropriate diagnostic evaluation. Am Jour Dis Child. 1981; 135: 431-433. 